\title{
Afavorita, entre o dramalhão e o lúdico Experimentos na representação de gêneros, ousadia no retrato das relações familiares e descaso do verossímil
}

Sandra Fischer e Geraldo Carlos Nascimento

\section{Resumo}

Este trabalho, decorrente de uma pesquisa em andamento, tem o propósito de discutir e levantar dados para um estudo da telenovela. A favorita (2008/2009, João Emanuel Carneiro, Rede Globo de Televisão), que ora tomamos como corpus, considera aspectos atinentes, entre outros, à questão da discussão e da representação dos lugares e papéis nas relações de gênero e no âmbito da família, e aos valores a eles vinculados. Ao misturar elementos do dramalhão tradicional com soluções do humor farsesco, a telenovela coloca sutilmente entre parênteses o parâmetro da verossimilhança e introduz um aspecto novo para as narrativas do horário: a exploração do lúdico e da experimentação.

Palavras-chave

Telenovela. Relações de gênero. Família. Narratividade. Verossimilhança.

Sandra Fischer I sandrafischer@uol.com.br

Universidade Tuiuti do Paraná. Docente e pesquisador vinculado ao Programa de Mestrado e Doutorado em Comunicação e Linguagens da Faculdade de Ciências Sociais Aplicada da Universidade Tuiuti do Paraná.

Geraldo Carlos Nascimento I geraldo.carlos@uol.com.br Universidade Paulista. Docente e pesquisador vinculado ao Programa de Mestrado em Comunicação da Universidade Paulista-UNIP.

\section{Introdução}

Com este trabalho pretendemos dar continuidade ao nosso propósito de discutir e levantar dados para um estudo sobre alterações na narratividade que vem ocorrendo na teleficção brasileira, particularmente nas telenovelas apresentadas pela Rede Globo de Televisão no chamado horário nobre. Situa-se no âmbito de um projeto de pesquisa em que nos ocupamos do produto midiático constituído pela telenovela, elemento de presença marcante e influente tanto na esfera restrita à cultura das mídias quanto na dimensão mais ampla da realidade social.

0 presente texto segue, assim, a trilha inaugurada pelo trabalho que realizamos a partir da telenovela Belíssimaa , de Sílvio de Abreu, produzida pela Rede Globo de Televisão e exibida entre novembro de 2005 e julho de 2006 - 0 qual foi sucedido pelo texto produzido a partir da telenovela Duas caras $^{2}$, de Aguinaldo Silva, também da Rede Globo, exibida de outubro de 2007 a maio de 2008. Concentramo-nos, agora, em 
Afavorita, de João Emanuel Carneiro, exibida de 02 de junho de 2008 a 16 de janeiro de 2009, telenovela que sucedeu Duas Caras.

É sabido que entre os anos 1970 e 1990 a teleficção no Brasil sofreu, de modo geral com avanços e recuos, uma chamada modernização - entendida pela crítica televisiva como ligada à construção e elaboração de um modelo de telenovelas que buscou deixar de lado a fórmula radiofônica dos melodramas cubanos e mexicanos ${ }^{3}$. Parece-nos que a década de 1990 e os anos 2000, por sua vez, têm sido tempos marcados pela consolidação dessas mudanças e por certa amplificação dessa dita modernizaçã $0^{4}$. Assim, dentro dos limites impostos pelo gênero, as telenovelas do horário vêm incorporando soluções relativamente mais realísticas e um tanto mais ousadas do que aquelas costumeiramente adotadas. Interessa-nos ressaltar particularmente 0 caso atinente à novela das oito justamente porque se trata, no caso da emissora em pauta, de um segmento telenovelístico que se caracterizava por apresentar perfil mais próximo do tradicional gênero folhetinesco: ou seja, tende a ser mais conservador, preenchido por narrativas de caráter mais ortodoxo ou sisudo, comprometidas com temáticas tidas como sérias e adultas.

Nossa hipótese, já apresentada e discutida em trabalhos anteriores, é de que desde a década de 90 as telenovelas do horário vêm acentuando, em maior ou menor escala, as rupturas com a tradição, e, não obstante a diversidade temática apresentada, um eixo estrutural mais ou menos amplo tem se reiterado no horário: a exploração narrativa do que identificamos como duplicidade, ou como ambiguidade, que parece ser favorecida pelo modo de produção não-linear; sem deixar de lado ainda possíveis alterações formais.

Belíssima, por exemplo, não apenas encetou discussões que questionaram posturas estereotipadas de poder e de relacionamentos profissionais, familiares e amorosos, como também apresentou inovações que, mesmo operadas de maneira algo sutil, resultaram em rupturas que promoveram a pulverização de posições e papéis tradicionais; o desenvolvimento narrativo conduzido de maneira pouco previsível, pontilhado por descontinuidades e inserções

Texto publicado no número 7 da revista Comunicação Midiática sob o título Belíssima: a um passo da ambiguidade considerações sobre conservadorismo e mudança na novela das oito.

0 referido texto foi publicado no número 30 da Significação - Revista de Cultura Audiovisual sob o título As múltiplas faces de Duas caras: telenovela e contemporaneidade, e anteriormente apresentado e discutido no GT Cultura das Mídias, no encontro de 2008 da Associação Nacional dos Programas de Pós-graduação em Comunicação.

A esse respeito, ver: Xavier (2004).

Alguns estudiosos, como Maria Immacolata Vassallo de Lopes (2005), chamam a atenção para as mudanças que se deram a partir de 1990 atribuindo-as a uma crise vivenciada pela Rede Globo de Televisão com o fim do regime militar e a introdução da TV a cabo; época em que a emissora viu-se obrigada a enfrentar de modo particularmente acentuado também a concorrência da Rede Manchete e do SBT. 
atípicas; e, destacadamente, a constituição e colocação em cena de personagens ambíguas, construídas de forma multifacetada, ostentando comportamentos por vezes incomuns e quase sempre pouco apreensíveis do ponto de vista dos valores envolvidos e colocados em questão no perfil psicológico de personagens televisivas.

\section{Em Páginas da vida ${ }^{5}$, sucessora de Belíssima,} verificou-se também uma boa dose de ambiguidade na construção das personagens: priorizando especificamente a figura daquelas que ocupavam os lugares do vilão, a telenovela relativizou as malfeitorias por elas realizadas, discutindo os motivos e pontos de vista que redundaram na prática de ações de caráter pouco ou nada louvável.

Paraíso tropical ${ }^{6}$, por sua vez, sucedendo Páginas da vida, parece ter tomado a orientação do rumo seguido por Belíssima: novamente observam-se personagens relativamente ambíguas, vilões divididos, e heróis às vezes um tanto maus ou inescrupulosos; o que chamou mesmo a atenção, todavia, foi a agilidade - pouco usual no gênero - com que se atavam e desatavam os nós da trama narrativa e o permanente deslocamento do foco de atenções, que escorregava, por entre os capítulos, de uma personagem para outra ao sabor dos conflitos que se estabeleciam e, rapidamente resolvidos, se desfaziam: o recurso enfaticamente utilizado demonstrou claramente que a narrativa optava por abandonar a prática usual de manter em suspenso um indefectível gancho para, presumivelmente, segurar 0 espectador até o último capítulo, quando então tudo se resolveria.

Duas caras, a sucessora de Paraíso tropical, apresentou inovações que se desdobraram em duas vertentes principais: uma no nível da tecnologia, posto que foi a primeira telenovela a ser produzida inteiramente com recursos da digitalização; e outra no nível de sua estruturação temática, que colocou explicitamente em pauta, já desde 0 título, a questão da ambivalência e da multiplicidade que estrutura a contemporaneidade e tende a reger 0 viver junto na atualidade.

Entendida como qualidade característica daquilo que é ambíguo, pouco apreensível ${ }^{7}$ a ambiguidade, como já salientamos em outro lugar, é própria da arte, da metáfora, favorece a quebra de expectativas e a plurissignificação que acompanham as rupturas poéticas - 0 que não seria exatamente conveniente, a julgar pela

Telenovela de Manoel Carlos produzida e veiculada pela Rede Globo de Televisão de 10 de julho de 2006 a 03 de março de 2007.

Telenovela de Gilberto Braga e Ricardo Linhares produzida e veiculada pela Rede Globo de Televisão de 05 de março a 29 de setembro de 2007.

No artigo sobre Belíssima, aqui referido, procuramos problematizar e desenvolver mais a fundo a questão da ambiguidade nas telenovelas. 
ótica da telenovela tradicional, para narrativas que necessitam da adesão de um espectro amplo de público que tanto acompanhe o desenrolar dos capítulos quanto seja suscetível ao pacote de ofertas de consumo que vem a eles atrelado. Em outras palavras: seria aconselhável evitar figuras e situações ambivalentes, posto que dificilmente poder-se-ia esperar que telespectadores préocupados com a instabilidade de personagens "enroladas" fossem seduzidos e compelidos à aquisição de produtos ou modus vivendi que implicassem hábitos de consumo interessantes a anunciantes e patrocinadores. Essa lógica, no entanto, como temos enfatizado em outros trabalhos, já não perdura de todo.

No caso de Afavorita, como a exemplo do que se viu em Duas caras, deparamo-nos com personagens multifacetadas, em certa extensão desprovidas das idealizações e das simplificações maniqueístas características do formato narrativo tradicional: personagens lidando com entraves típicos da fragilidade humana e dos problemas e questionamentos enfrentados pelas pessoas ditas comuns - recurso que tende tanto a fortalecer mecanismos crítico-solidários de identificação do público com as histórias narradas (em detrimento da mera adesão contemplativa passível de resultar em plena suspensão da descrença e do juízo crítico) quanto a incentivar o desenvolvimento de posturas favoráveis a atitudes de tolerância, compartilhamento ou crítica solidário-construtiva. Mais ainda - e principalmente - 0 folhetim de João Emanuel
Carneiro enfoca e discute, a partir da exploração das relações de gênero e dos papéis familiares, as possibilidades de subversão de valores tradicionais.

\section{A favorita: lugares, movimento e subversão}

Não obstante os limites impostos pelo gênero telenovela, em Afavorita a questão contemporânea das diversas perspectivas da pluralização e do intercâmbio de papéis e de lugares sociais, atrelada às consequentes e sucessivas variações da máscara ou modo de se dar a ver dos personagens, afigura-se como 0 foco privilegiado da narrativa.

A história é desencadeada a partir da dissolução de uma dupla caipira constituída por duas jovens cantoras que, desde a infância, convivem como se fossem irmãs. Flora e Donatela encontram-se no auge da carreira quando a mais talentosa das duas, a bela e estabanada Donatela, decide largar o ofício para se casar com Marcelo Fontini, o abonado herdeiro de uma poderosa indústria de celulose. Obcecada pela parceira, sentindo-se rejeitada e abandonada, Flora seduz-lhe o marido, do qual se torna amante e, não muito tempo depois, acaba por assassiná-lo. Na época do crime, pelo qual é julgada e condenada, Flora já é mãe de uma criança de outro homem com quem se casara - Dodi -, mas consegue fazer com que todos acreditem que a menina é filha de Marcelo. Donatela torna-se mãe adotiva 
da menina, acreditando que a pequena Lara é filha de seu marido assassinado. Vinte anos mais tarde, ao terminar de cumprir sua pena, Flora deixa o presídio e, fingindo ter sido barbaramente injustiçada, passa a atormentar a antiga companheira, tratando de culpá-la pela morte de Marcelo e por diversos outros crimes que, no desenrolar da trama, viria a cometer. Tanto faz que consegue colocá-la na prisão, e assume o lugar que a outra ocupava junto à poderosa família Fontini. Desacreditada, desprezada e isolada, Donatela passa por uma longa série de sofrimentos, atribulações e transformações até conseguir, finalmente, provar sua inocência e recuperar o lugar que havia sido seu.

Até certa altura da narrativa, o público não sabe quem é, efetivamente, a vilã da história: Flora ou Donatela? À moda de um jogo, várias pistas simultâneas, ambíguas e contraditórias, são indicadas de maneira a instalar uma diversidade de dúvidas e a provocar uma série de confusões. Inicialmente, a simpática Flora parece ser a vítima sofredora e humilde, enquanto a voluptuosa Donatela, que fica com o ex-marido da outra, o falsário e trambiqueiro Dodi, se afigura como uma mulher ambiciosa e inescrupulosa, disposta a tudo para manter sua abastada condição financeira e a consequente posição social de destaque. Uma acusa a outra pela morte de Marcelo. As demais personagens dividem-se, juntamente com os telespectadores, entre as duas protagonistas. À medida que os capítulos se desenvolvem e que a trama se vai adensando e complexificando, multiplicam-se as evidências contra Donatela e a figura de Flora consolidase como "mocinha". Quando a virtude parece definitivamente alinhar-se com esta última, têm início cenas nas quais se acentuam oscilações de comportamento de uma e de outra: a dúvida, então, é novamente instalada - até o ponto em que Flora revela-se como a bandida francamente calculista, inescrupulosa e cruel, enquanto Donatela se afirma como uma mulher de boa índole e de bons princípios, maternal, dedicada à filha adotiva, apegada à vida em família - ambiciosa, sim, mas honesta e também um tanto ingênua e simplória.

Ao longo da narrativa, até mesmo no limite dos momentos finais, em diversas e sucessivas oportunidades as posições ameaçam inverterse novamente: há momentos em que a perversa Flora inspira pena enquanto o perfil bondoso de Donatela reveste-se de certa dose de crueldade. 0 vice-versa implacável impera na diegese: protagonistas e personagens trocam constantemente de lugar na trama narrativa, de modo que perspectivas e pontos de vista são alternados e alterados o tempo todo. No mesmo movimento, os sentimentos e as preferências que a audiência tende a nutrir e a manifestar face às personagens e às situações por elas protagonizadas acabam desestabilizados por conta da frequência com que são expostos às modificações ou abalos nos rumos da história. 
Ao final das contas, Flora acaba sendo claramente caracterizada como psicopata, traumatizada pelas dificuldades e rejeições sofridas no período da infância e na época da juventude - 0 que, em certa extensão, relativiza um pouco o peso das atrocidades que comete. A trajetória da personagem Donatela, por seu turno, faz pensar que nem sempre a ambição e 0 gosto pela vida farta e confortável implicam, necessariamente, mau-caratismo, perversidade e vilania. 0 perfil de cada uma das protagonistas, assim, adquire nuances e sutilezas e, em alguma medida, faz com que ambas as personagens escapem do enredamento simplista, usual em telenovelas, que rotula umas como irremediavelmente más e outras como imaculadamente virtuosas.

Por mais inverossímeis ou mesmo francamente absurdas que se revelem muitas das peripécias e situações apresentadas no folhetim, o clima de artificialismo e exagero melodramático é temperado por uma aragem algo inovadora, cujos efeitos oscilatórios e ambivalentes podem ser percebidos ao longo dos capítulos de A favorita - a partir já da própria vinheta de abertura dos capítulos, composta por uma animação que tematiza, ao som de um tango argentino $0^{8}$, a instabilidade da situação das personagens, a pluralidade de pontos de vista e 0 dinamismo das oposições entrecortadas que pontuam a tessitura da trama e orientam o desenvolvimento dramático, que incorpora, pelo exagero no andamento de determinadas situações, certa dose de ironia.

\section{$3 \boldsymbol{A}$ favorita e as relações de gênero: subversão e movimento}

A confusão multifacetada e plural que constitui tanto as figuras das duas protagonistas quanto a permuta entre os lugares que ocupam e os papéis que desempenham estende-se às figuras das demais personagens e às situações em que se inserem. As relações de gênero, assim, por vezes orientam-se para direções e abordagens pouco convencionais ou mesmo atípicas em termos telenovelísticos. Os pares amorosos, a princípio, não se formam e nem se estabelecem com firmeza; o jovem garanhão finge ser homossexual e 0 jovem homossexual finge ser heterossexual - até que se apaixona por uma bela jovem - grávida do garanhão, por sinal - para, ao final da novela, aderir voluntariamente ao casamento hétero e ao papel de pai de um filho que não é seu; a adolescente grávida, em lugar de padecer as agruras da clássica e didática estigmatização por parte de todos os amigos e colegas, torna-se objeto da paixão de um adolescente que se dispõe a casarse com ela e a assumir o lugar de pai do bebê, sem se importar que a amada se mantenha firme em sua determinação de não revelar a identidade do pai de seu filho - em alguns momentos, diga-se, pairou no ar até a possibilidade de incesto. Relações triádicas ou mesmo múltiplas articulam-se na trama em relativa placidez, com 
o conhecimento e aquiescência dos envolvidos: uma das personagens femininas mantém relações amorosas com dois homens, é mãe do filho de um terceiro, apaixona-se por um quarto e termina 0 folhetim vivendo em romântica harmonia com os dois primeiros - que se consideram, ambos, pais de seu filho. Nenhum dos envolvidos, ressalte-se, encaixa-se na axiologia subjacente a inúmeras telenovelas para designar a categoria dos devassos e desajustados sexuais, pelo contrário: tais personagens são apresentados como pessoas sensíveis, afetivas, conscientes de seus atos. A dona de casa suburbana e convencional, inicialmente submissa aos desmandos de um marido monstruoso, chega ao fim da trama sem mágoas ou rancores, sozinha, feliz: liberta-se do casamento opressivo, rejeita uma nova união com um pretendente amoroso e afável e mostra-se pronta a fortalecer laços afetivos com uma amiga assumidamente homossexual. Homens jovens envolvidos em relacionamentos com mulheres maduras, machões inveterados que se revelam sexualmente frágeis ou impotentes, casais maduros e consolidados abrindo mão da estabilidade conjugal para arriscar a troca de parceiros, maridos e esposas que passam a ser amantes e tornam a ser maridos e esposas tradicionais.

\section{A favorita e a família: lugares desestabilizados (em movimento)}

Na mesma perspectiva em que se orientam as relações de gênero delineiam-se as configurações familiares. Se é fato que a base do modelo tradicional de família - formado por pai, mãe e filhos - está longe de ter sido banida de $A$ favorita, é fato também que a fisionomia de tal modelo parece ter sido, ali, consideravelmente alterada. A telenovela desenvolve-se pontilhada de grupamentos familiares compostos de dois pais e nenhuma mãe, filhos criados por mães solitárias, mães que rejeitam filhos verdadeiros, mães postiças que se revelam mais maternais do que mães verdadeiras, mães e pais solteiros, filhos adolescentes que tomam conta de pais perturbados ou imaturos, irmãos que não são filhos dos mesmos pais, pais que preferem filhos adotivos a filhos verdadeiros, cunhados que se envolvem em relações amorosas com cunhadas, avós que ocupam o lugar de pais, avós tido como verdadeiros que se revelam postiços, netos verdadeiros prejudicados em benefício de netos postiços, pais que logram filhos e filhos que rejeitam pais, prostitutas que se transformam em esposas e matriarcas respeitáveis, esposas bem casadas que saem em busca de aventuras sexuais com os amigos do marido, casais com uma única mãe e com sogra nenhuma - e por aí vai.

Em manifestação pouco comum em telenovelas - principalmente em se tratando da novela das oito - e muito à moda dos filmes do cineasta espanhol Pedro Almodóvar ${ }^{9}$, os laços familiares se fazem e se desfazem regidos

Este realizador foi responsável por filmes inovadores e irreverentes, sobretudo no que diz respeito aos valores familiares, entre os quais destacam-se Mulheres à beira de um ataque de nervos, A lei do desejo, Tudo sobre minha mãe, Carne trêmula, Fale com ela, entre outros. 
muito mais pelos afetos e pelas circunstâncias do que pelas convenções e conveniências prédeterminadas - de modo que o estabelecimento de lugares acaba sendo destituído da rigidez característica em prol da formação de uma rede flexível e ondulante de relações topológicas. Consequentemente, os papéis correspondentes a cada lugar se relativizam e se intercambiam consideravelmente, fazendo com que as relações sociais tradicionais sejam colocadas em xeque, questionadas e, até certo ponto, subvertidas.

A família foi, pode-se dizer, personagem destacado na telenovela A favorita. Não exatamente a família tradicional, regular e convencional, mas uma família que se estabelece e se articula, configurando-se em redes de relacionamentos flutuantes e lábeis que se intercambiam e se interpenetram no tempo e no espaço; redes formadas por fios e nós que se fazem e se desfazem, apertados e afrouxados conforme as circunstâncias e conveniências afetivas, psicológicas, e espaçotemporais. A família favorita da telenovela $A$ favorita foi, assim, a família carnavalizada, flutuante, articulando-se em um permanente festival de cenas e quadros que delineiam um agrupamento reimaginado - familiar, de resto, a um considerável número de famílias existentes nas sociedades contemporâneas.

Misturam-se, assim, em complexos e intrincados relacionamentos, uma gama variada de casais e de parceiros amorosos que se reproduzem dando origem a uma gama variada de filhos naturais, legítimos, adotados, bastardos; irmãos e parceiros amorosos, avós e netos, pais e filhos - dentre os diversos exemplos observáveis na trama, destacam-se, entre outros, a dupla Orlandinho e Maria do Céu (ele um ricaço homossexual e ela uma paupérrima garota de programa), que estabelece um casamento de aparências e acaba se apaixonando um pelo outro - a despeito das preferências sexuais manifestadas inicialmente por Orlandinho; 0 casal de adolescentes Mariana e Shiva Lênin (ela a mãe precoce, obstinada em não revelar a ninguém a paternidade de seu bebê, ele 0 namorado disposto a assumir a criança como filha); 0 agrupamento familiar constituído por Augusto César, Elias, Rosana e Shiva Lênin, no qual Augusto César e Elias, ambos companheiros de Rosana, são igualmente considerados pais de Shiva - o qual teria sido, ao final das contas, fruto de um relacionamento de Rosana com um terceiro homem - 0 argentino Pepe, um ex-namorado de Rosana?, nada há, porém, de conclusivo a respeito -; 0 agrupamento formado pela ex-manicure Cilene, o jovem Halley e as garotas de programa da casa que Cilene dirige: mãe de criação de Halley, Cilene atua como um misto de amorosa mãe-cafetina para as meninas, enquanto Halley comporta-se como um híbrido de irmão-namorado-amigo das garotas; o quinteto Donatela, Flora, Marcelo, Dodi e Zé Bob: Donatela e Flora, criadas como irmãs pelo pai de Flora, Marcelo e Dodi, amigos um do outro; em um tempo que antecede ao início da 
narrativa, casa-se com Marcelo a primeira e com Dodi a segunda; Marcelo tem um caso amoroso com Flora, e Dodi, após a morte de Marcelo, vem a se casar com Donatela; no decorrer da novela, Dodi volta a unir-se a Flora enquanto Donatela une-se ao jornalista Zé Bob - com quem Flora tivera também um envolvimento amoroso; 0 trio constituído pelo rico e poderoso empresário Gonçalo, pela culta e abonada dona de casa Irene e pelo operário sindicalista Copolla: em época remota, que antecede ao início do tempo diegético, os dois apaixonaram-se por Irene, que inaugura a trama como esposa de Gonçalo e acaba a novela prestes a contrair novas núpcias com Copolla.

À moda de móbiles ou módulos que se encaixam e desencaixam conforme as circunstâncias e conveniências, as personagens se movimentam por entre relações que se articulam, digamos, rizomaticamente. Assim, os tradicionais lugares e papéis familiares, convencionais e pré-estabelecidos, tornam-se cambiantes e ficam consideravelmente relativizados. Irmãos desdobram-se em amigos e amantes, avós funcionam como pais, as figuras de sogros e pais hibridizam-se e colam-se na mesma personagem, tios se transmudam em cunhados e colegas, primos viram tios ou irmãos - e por aí vai. A representação de tais lugares e papéis, consequentemente, na medida em que encena na tela da televisão, em meio à domesticidade da rotina cotidiana do jantar familiar, famílias carnavalizadas, desordenadas, coloca em pauta e discute a possibilidade de agrupamentos familiares inusitados, experimentais - o que acaba por questionar e colocar em xeque a estabilidade do sistema narrativo instituído e, por vias de consequência, questiona e coloca em xeque também os valores a ele agregados.

As inverossimilhanças de inúmeras situações de Afavorita incomodaram parte da audiência, embora isso não tenha chegado, de acordo com os números, a refletir negativamente nos índices do Ibope - o pico da audiência chegou a mais de 50 pontos na última semana de apresentação e a média foi mantida acima dos 40 pontos, 0 patamar desejado pela emissora para a faixa horária em questão. A convocação do lúdico sim é que talvez não tenha rimado muito bem com o formato previsto: passa longe das intrigas dos chamados dramalhões, cuja estrutura dramática, sobejamente conhecida e criticada, no entanto, ainda parece fazer falta àqueles que já tinham comodamente estabelecido, embora pelo negativo, quais regras - ou seriam antes prescrições? - deveriam balizar o gênero. A considerável predominância do lúdico em pleno horário das oito da noite configurou, certamente, uma novidade significativa introduzida pela telenovela A favorita. Resta saber se fará escola. As novidades na teleficção, não obstante estarmos assistindo a um ritmo acelerado de alterações no formato, se fazem aos poucos, numa espécie de contradança, em que a cada avanço corresponde um ou dois passos atrás, até que se 
retome ao ponto anterior. Isso talvez se explique pelo compromisso que a televisão mantém em relação ao público e aos anunciantes. Os índices do Ibope são fundamentais para que qualquer inovação venha a ser ou não aceita. Daí os cuidados necessários; afinal, não se pode mexer em time que está ganhando. Considerando-se esse aspecto, A favorita foi bastante ousada e chegou a desagradar parte significativa da audiência, embora os números não lhe tenham sido desfavoráveis quando comparado às últimas produções do horário. A incorporação das alterações detectadas no formato, no entanto, requer ainda outros "testes", muito embora o perfil conservador, que ainda rege o gosto predominante do público, tenha dado mostras de mudancas.

\section{Referências}

BALOGH, Anna Maria. 0 discurso ficcional na TV. São Paulo: EDUSP, 2002.

DANIEL FILHO. 0 circo eletrônico: fazendo TV no Brasil. Rio de Janeiro: Jorge Zahar, 2003.

FISCHER, Sandra. Cria cuervos e Todo sobre mi madre: família, cinema e subversão. Significação -

Revista Brasileira de Semiótica, São Paulo, n. 21, p. 43-61, 2004.

; NASCIMENTO, Geraldo Carlos do. As múltiplas faces de Duas caras: telenovela e contemporaneidade. Significação: Revista de Comunicação Audiovisual, São Paulo, n. 30, p. 9-23, 2008.

Belíssima: a um passo da

ambigüidade - considerações sobre conservadorismo e mudança na novela das oito. Revista Comunicação Midiática, Bauru, n. 7, p. 49-63, 2007.
HAMBURGUER, Esther. 0 Brasil antenado: a

sociedade da novela. Rio de Janeiro: Jorge Zahar, 2005.

LOPES, Maria Immacolata Vassallo de. (Org.)

Telenovela: internacionalização e interculturalidade. São Paulo: Loyola, 2004.

LOPES, Maria Immacolata Vassallo de. Narrativas televisuais e identidade nacional: 0 caso da telenovela brasileira. In: BUONANNO, Milly (orgs.).

Comunicação social e ética: colóquio Brasil-Itália. São Paulo: Intercom, 2005, p. 250-273.

MACHAD0, Arlindo. Arte e mídia. Rio de Janeiro: Jorge Zahar, 2007.

MARTÍN-BARBERO, Jesús. Viagens da telenovela: dos muitos modos de viajar em, por, desde e com a telenovela. In: LOPES, Maria Immacolata Vassallo de (org.) Telenovela: internacionalização e interculturalidade. São Paulo: Loyola, 2004, p. 23-46.

MARTÍN-BARBER0, Jesús; REY, Germán. Los ejercicios del ver: hegemonía audiovisual y ficción televisiva. Barcelona: Gedisa, 1999.

MOISÉS, Massaud. Dicionário de termos literários. São Paulo: Cultrix, 1999.

ROUDINESC0, Elisabeth. A família em desordem. Rio de Janeiro: Jorge Zahar, 2003.

XAVIER, Ismail. Do senso moral-religioso ao senso comum pós-freudiano: imagens da história nacional na teleficção brasileira. In: LOPES, Maria Immacolata Vassallo de. (Org.) Telenovela: internacionalização e interculturalidade. São Paulo: Edições Loyola, 2004. p. 47-73. 
A favorita, between the melodramatic and the ludic

Experiments concerning the representation of gender relations, family relations and verisimilitude

\section{Abstract}

This paper, part of a research project focusing soap-opera, intends to raise and discuss preliminary information and remarks. The corpus for the present study consists on the soap-opera A Favorita (Brasil, 2008/2009, João Emanuel Carneiro, Rede Globo de Televisão), which deals with aspects and values attached to the problem of representation of places and roles considering the sphere of family and gender relations. Mixing up traditional melodramatic elements and comic devices, A Favorita places verossimility parameters in parentheses and introduces a new narrative feature into the evening schedule soap-opera: the exploration of ludicity and experimentalism.

\section{Keywords}

Soap opera. Gender relations. Family.

Narrativity. Verisimilitude.

\section{A favorita, entre el melodrama y lo lúdico}

Experimentos en la representación de género, osadía en el retrato de las relaciones familiares $y$ el poco caso a lo verosímil

\section{Resumen}

Este trabajo que transcurre de una investigación en desarrollo, tiene el propósito de discutir y levantar datos para un estudio de la telenovela. La Favorita (2008/2009, João Emmanuel Carneiro, Rede Globo de Televisão) y que ahora tomamos como corpus, considera aspectos que se detienen, entre otros, a la cuestión de la discusión y de la representación de los locales y papeles en las relaciones de género en el ámbito de la familia y a los valores a eso vinculados. Al mezclar elementos del dramón tradicional con soluciones del humor farsesco la telenovela emplaza sutilmente entre paréntesis el parámetro de la verosimilitud e introduce un aspecto nuevo a las narrativas del horario en que se presentan: la explotación del lúdico y de la experimentación.

\section{Palabras clave}

Telenovela. Relaciones de género. Familia. Narratividad. Verosimilitud. 


\section{Expediente}

A revista E-Compós é a publicação científica em formato eletrônico da Associação Nacional dos Programas de Pós-Graduação em Comunicação (Compós). Lançada em 2004, tem como principal finalidade difundir a produção acadêmica de pesquisadores da área de Comunicação, inseridos em instituições do Brasil e do exterior.
E-COMPÓS I www.e-compos.org.br I E-ISSN 1808-2599

Revista da Associação Nacional dos Programas de Pós-Graduação em Comunicação. Brasília, v.12, n.3, set./dez. 2009.

A identificação das edições, a partir de 2008 passa a ser volume anual com três números.

\section{CONSELHO EDITORIAL}

Afonso Albuquerque

Universidade Federal Fluminense, Brasil

Alberto Carlos Augusto Klein

Universidade Estadual de Londrina, Brasi

Alex Fernando Teixeira Primo

Universidade Federal do Rio Grande do Sul, Brasil

Alfredo Vizeu

Universidade Federal de Pernambuco, Brasi

Ana Carolina Damboriarena Escosteguy

Pontifícia Universidade Católica do Rio Grande do Sul, Brasil

Ana Silvia Lopes Davi Médola

Universidade Estadual Paulista, Brasil

André Luiz Martins Lemos

Universidade Federal da Bahia, Brasil

Ângela Freire Prysthon

Universidade Federal de Pernambuco, Brasil

Antônio Fausto Neto

Universidade do Vale do Rio dos Sinos, Brasil

Antonio Carlos Hohlfeldt

Pontifícia Universidade Católica do Rio Grande do Sul, Brasil

Arlindo Ribeiro Machado

Universidade de São Paulo, Brasil

César Geraldo Guimarães

Universidade Federal de Minas Gerais, Brasi

Cristiane Freitas Gutfreind

Pontifícia Universidade Católica do Rio Grande do Sul, Brasil

Denilson Lopes

Universidade Federal do Rio de Janeiro, Brasil

Eduardo Peñuela Cañizal

Universidade Paulista, Brasil

Erick Felinto de Oliveira

Universidade do Estado do Rio de Janeiro, Brasil

Francisco Menezes Martins

Universidade Tuiuti do Paraná, Brasil

Gelson Santana

Universidade Anhembi/Morumbi, Brasil

Goiamérico Felício

Universidade Federal de Goiás, Brasil

Hector Ospina

Universidad de Manizales, Colômbia

Herom Vargas

Universidade Municipal de São Caetano do Sul, Brasil

leda Tucherman

Universidade Federal do Rio de Janeiro, Brasil

Itania Maria Mota Gomes

Universidade Federal da Bahia, Brasil

Janice Caiafa

Universidade Federal do Rio de Janeiro, Brasil

Jeder Silveira Janotti Junior

Universidade Federal da Bahia, Brasil

\section{João Freire Filho}

Universidade Federal do Rio de Janeiro, Brasil

John DH Downing

University of Texas at Austin, Estados Unidos

José Luiz Aidar Prado

Pontifícia Universidade Católica de São Paulo, Brasil

José Luiz Warren Jardim Gomes Braga

Universidade do Vale do Rio dos Sinos, Brasi

Juremir Machado da Silva

Pontifícia Universidade Católica do Rio Grande do Sul, Brasil

Lorraine Leu

University of Bristol, Grã-Bretanha

Luiz Claudio Martino

Universidade de Brasília, Brasil

Maria Immacolata Vassallo de Lopes

Universidade de São Paulo, Brasil

Maria Lucia Santaella

Pontifícia Universidade Católica de São Paulo, Brasil

Mauro Pereira Porto

Tulane University, Estados Unidos

Muniz Sodre de Araujo Cabral

Universidade Federal do Rio de Janeiro, Brasil

Nilda Aparecida Jacks

Universidade Federal do Rio Grande do Sul, Brasil

Paulo Roberto Gibaldi Vaz

Universidade Federal do Rio de Janeiro, Brasil

Renato Cordeiro Gomes

Pontifícia Universidade Católica do Rio de Janeiro, Brasil

Ronaldo George Helal

Universidade do Estado do Rio de Janeiro, Brasil

Rosana de Lima Soares

Universidade de São Paulo, Brasil

Rossana Reguillo

Instituto Tecnológico y de Estudios Superiores do Occidente, México

Rousiley Celi Moreira Maia

Universidade Federal de Minas Gerais, Brasil

Samuel Paiva

Universidade Federal de São Carlos, Brasil

Sebastião Albano

Universidade Federal do Rio Grande do Norte, Brasil

Sebastião Carlos de Morais Squirra

Universidade Metodista de São Paulo, Brasil

Simone Maria Andrade Pereira de Sá

Universidade Federal Fluminense, Brasi

Suzete Venturelli

Universidade de Brasília, Brasil

Valério Cruz Brittos

Universidade do Vale do Rio dos Sinos, Brasil

Veneza Mayora Ronsini

Universidade Federal de Santa Maria, Brasil

Vera Regina Veiga França

Universidade Federal de Minas Gerais, Brasi

\section{COMISSÃO EDITORIAL}

Felipe da Costa Trotta I Universidade Federal de Pernambuco, Brasil Rose Melo Rocha I Escola Superior de Propaganda e Marketing, Brasil

\section{CONSULTORES AD HOC}

Arthur Autran Franco de Sá Neto I Universidade Federal de São Carlos

Carlos Eduardo Franciscato I Universidade Federal de Sergipe

Elisa Reinhardt Piedras I Universidade Federal do Rio Grande do Su

Elizabeth Bastos Duarte I Universidade Federal de Santa Maria

Marcia Benetti Machado I Universidade Federal do Rio Grande do Sul

Sandra Maria Lúcia Pereira Gonçalves I Universidade Federal do Rio Grande do Sul

Suzana Kilpp I Universidade do Vale do Rio dos Sinos

Tattiana Gonçalves Teixeira I Universidade Federal de Santa Catarina

Vander Casaqui I Escola Superior de Propaganda e Marketing

Vicente Gosciola I Universidade Anhembi Morumbi

Walter Teixeira Lima Junior I Fundação Cásper Líbero

REVISÃO DE TEXTO E TRADUÇÃO I Everton Cardoso

EDITORAÇ̃̃ ELETRÔNICA I Raquel Castedo
COMPóS I www.compos.org.br

Associação Nacional dos Programas de Pós-Graduação em Comunicação

Presidente

Itania Maria Mota Gomes

Universidade Federal da Bahia, Brasil

itania@ufba.br

Vice-presidente

Julio Pinto

Pontifícia Universidade Católica de Minas Gerais, Brasil

juliopinto@pucminas.br

Secretária-Geral

Ana Carolina Escosteguy

Pontifícia Universidade Católica do Rio Grande do Sul, Brasil

carolad@pucrs.br 